Montañés, R. (2021): Ensayo sobre la Iliada (Bartolomé Segura Ramos), Sevilla: Thémata, 2020, 289 págs. ISBN

978-84-943454-63. Cultura, Lenguaje y Representación, Vol. xxv, 333-336

ISSN $1697-7750 \cdot$ E-ISSN 2340-4981

DOI: http://dx.doi.org/10.6035/clr.2021.25.19

\title{
Reseñas / Book reviews
}

Ensayo sobre la Ilíada, (Bartolomé Segura Ramos), Sevilla: Thémata, 2016, 289 págs. ISBN 978-84-943454-63. $18 €$. Reseñado por Rubén J. Montañés, Universitat Jaume I. ORCID: https://orcid.org/0000-0002-0726-6667.

Reseña recibida el / Review received: 2021-02-02

Reseña aceptada el / Review accepted: 2021-03-12

Cuando el prólogo de un libro con un título como el que nos ocupa comienza así...

De pocos libros se ha escrito tanto como de la Ilíada de Homero. Así es como se calcula que entre los Prolegómena de Wolf (1795) y el vasto comentario de Kirk y sus colaboradores (1995), es decir, un espacio de 200 años, se han publicado, entre artículos y libros, alrededor de 12.000 títulos sobre la obra, para leer y sustanciar los cuales se precisarían varios cientos de estudiosos.

...el lector tiene derecho a preguntarse: ¿realmente era necesario uno más? Pero la duda, en realidad, es de corto trayecto: han pasado al menos dos milenios y medio desde la fijación por escrito del texto que se denomina Ilíada, pero la fascinación que provoca en quien la lee, como antes la provocó en quienes la escuchaban, se mantiene intacta. Es dicha fascinación la que continúa suscitando tantas y tantas reflexiones e hipótesis; y por las especiales características de la obra, será siempre un objeto de estudio interesante y atractivo.

En esencia, Ensayo sobre la Ilíada constituye una serie de reflexiones sobre algunos aspectos de dicho poema homéri- co, que Bartolomé Segura articula en dos grandes bloques: la primera, dedicada al proceso de creación, y la segunda dedicada a lo que el autor denomina «el producto», subdividida a su vez en un apartado que trata de «la forma» y otro de «la semántica». En la primera parte podemos apreciar las muchas lecturas que hay detrás de este libro, ya desde su primer capítulo, que trata sobre los antecedentes orientales de la épica griega antigua en general, y de la Ilíada en particular. Podría decirse que el autor pasa revista a lo que al respecto dijeron los estudiosos del tema - que como ya se ha dicho, son una cantidad ingente. Esto es, sin duda, una aportación valiosa, un resumen de siglos que agradece quien se acerca al tema por vez primera; sin embargo, algunos defectos formales, fundamentalmente ortotipográficos, hacen la lectura más dificultosa de lo que sería deseable.

En primer lugar, la utilización del sistema Harvard de citación es inusitada. Si se opta por dicho sistema, las referencias deben ir en el cuerpo principal del texto, y no a pie de página; pero en este libro se mantienen en el pie, y sin embargo, en ocasiones, en dicho cuerpo principal aparecen indicaciones de paginación o incluso abreviaturas del sistema tradicional, 
del tipo ibidem u op. cit. Esto, unido a la ausencia de sangrados para destacar citaciones textuales - que se mantienen en el mismo tamaño de letra -, de un uso reduccionista de las comillas - únicamente utiliza las comillas llamadas «inglesas»y de un empleo un tanto anárquico de la cursiva, hacen algunos pasajes - por otra parte interesantísimos - confusos y difíciles de seguir; el lector pierde a menudo la conciencia de si lo que está leyendo lo dice el autor, o alguien que el autor cita, o - peor aún - se trata de una citación dentro de otra. La transliteración del griego o de otras lenguas también es en ocasiones defectuosa: desaparecen las cursivas, cuando es uno de los casos en que estas deben utilizarse sistemáticamente. Asimismo, la transcripción de antropónimos griegos presenta algún fallo, sobre todo en los femeninos terminados en -o, que al transcribirse no debe quedar acentuada: por ejemplo, Calipso y no *Calipsó, Leto y no *Letó. Flagrantemente incorrectos son algunos topónimos, como ${ }^{*}$ Cnosó o *Festó en lugar de Cnoso o Cnosos, Festo o Festos. Finalmente, el título de alguna obra de la Antigüedad no aparece en la forma sancionada por la tradición: Cantos chipriotas - con mayúscula a veces en el gentilicio, y a veces no - en lugar de los títulos más habituales en español Cantos ciprios o Ciprias; o Aspís de Hesíodo, en transliteración del griego, en lugar del más frecuente Escudo.

Todo ello, sin embargo, sería susceptible de fácil corrección; si esta se realizara alguna vez, sería deseable establecer, además, epígrafes y subepígrafes numerados según los distintos niveles para una mejor comprensión del lector, pues la materia es mucha y densa, y la exposición acertada; los defectos son en todo caso de forma, pero nunca de fondo. Del primer bloque en el que por demás queda claro que los temas, motivos, escenas típicas... de la Ilíada pertenecían a un acervo común a cantores del Mediterráneo oriental, e incluso de toda Asia Menor y Mesopotamia - ha de destacarse la acertada insistencia en considerar un ciclo formado por Cantos ciprios, la propia Ilíada, Etiópida, Pequeña Ilíada, Iliupersis, Nóstoi («regresos»), Odisea (un nóstos entre otros muchos, pero desarrollado «homéricamente») y Telegonía, aparentemente por ese orden; aunque de todos estos poemas, con excepción de la Ilíada y la Odisea, claro está, no se conserven sino fragmentos; de ellos se habla ordenadamente en el capítulo III de la sección «El sustrato épico», y en el capítulo $\mathrm{V}$ de la misma se rastrean los ecos de otros ciclos en la Ilíada.

El mismo buen sentido se aplica a las páginas dedicadas a la época, tanto del material como de la génesis de la Ilíada como tal. Sin duda, la idea de considerar los poemas homéricos, y en especial la Ilíada como una combinación de elementos literarios acumulados por superposición en el tiempo no es novedosa, pero el autor la clarifica y refrenda con las abundantes citas que aporta - pues lo confuso de las citaciones no disminuye en absoluto su acierto - y con las comparaciones que establece con otros textos épicos de otros tiempos, como la Chanson de Roland o el Cantar de Mio Cid. Por otra parte, las razones para una fijación relativamente tardía - época de Pisístrato - y en Atenas han ido ganando terreno las últimas décadas, lo que no debe confundirse con la existencia de un trabajo filológico de compilación y fijación encargado por el tirano; esta leyenda pretende atribuirle a Pisístrato atributos de mecenazgo propios de los reyes de época helenística. No debe extrañar, por lo demás, que apenas se invierta siete páginas en la figura de Homero; a estas alturas, su ficcionalidad y su falta de entidad histórica quedan ya fuera de duda.

El breve capítulo dedicado a la lengua de la Ilíada, aunque describa somera y ordenadamente sus rasgos arcaicos y sus características dialectales, adolece a nuestro entender de un punto de partida poco claro, tal vez motivado por una mala interpreta- 
ción del término «lengua artificial» (Künstliche Sprache). El autor parece interpretarlo como «lengua que no se entiende», y se lanza con premura innecesaria a demostrar lo contrario. Que una variedad lingüística - un dialecto, a fin de cuentas; recuérdese que $\delta i \alpha ́ \lambda \varepsilon \kappa \tau o \varsigma$ significa «elección» - no se hable ni se haya hablado jamás en un territorio concreto no significa que sea incomprensible; de hecho, como el mismo autor apunta, no tendría sentido que fuera incomprensible la lengua de un género poético narrativo, y que se basa en que el auditorio comprenda bien lo narrado. El hebreo moderno, por ejemplo, es un producto «artificial», como lo son buena parte de las variantes estandarizadas de muchas lenguas modernas: tienen precisamente de artificioso «elegir» las formas que todos los hablantes pudieran entender. En el caso de la lengua de la Ilíada bien podemos suponer algo parecido, aunque el criterio para introducir formas ajenas al dialecto jónico no fuera (solo) la comprensión, sino la adaptación al hexámetro dactílico.

Los capítulos II y III de «Los medios técnicos» se dedican a la oralidad y a la repetición, en diversos niveles, como procedimiento genérico de la composición y/o difusión oral. Nunca está de más, en efecto, recordar las condiciones en que se generó y se difundió durante largo tiempo la Ilíada; tal como la conocemos, es la fijación por escrito de un texto oral, y la mayor parte de sus supuestas inconsistencias se explican desde la oralidad. Así, la repetición: ya sea de grupos de versos, de un solo verso, de medio verso o de la asociación entre un sustantivo y un epíteto. El poeta de la cultura escrita crea con palabras - y puede, además, repasar lo escrito y cambiarlas o corregirlas - en tanto que el poeta de la oralidad crea con grupos de palabras de diversa extensión, y no puede volver atrás para reconsiderarlos: esa es, esencialmente, la diferencia.
Especialmente interesante parece, en coherencia con lo anteriormente expuesto, liberar de su estigma a las «interpolaciones», al menos a aquellas anteriores a Aristarco, que ya se encontró con un texto cerrado; las anteriores forman parte lícita del proceso de génesis de la Ilíada, ese proceso diacrónico acumulativo a que antes nos hemos referido. Lo contrario sería suponerle a la obra, desde la primera fase de su creación, una especie de copyright, una estabilidad que de ninguna manera se aviene con las circunstancias de esta.

Llegamos así a la primera sección, «La forma» del segundo bloque, «El producto». Claramente es la aportación más particular del autor y donde se pone de manifiesto su gran conocimiento de la Ilíada: las citaciones de otros autores disminuyen sensiblemente y se percibe que se encuentra cómodo en un medio que domina. La premisa de la que parte, y que desarrolla y argumenta «desde dentro» del texto homérico, es la siguiente: la Ilíada tal como la conocemos se formó combinando dos grandes poemas que tenían entidad previa por separado.

Así, el canto I - y el autor nos recuerda que existieron en la Antigüedad otros proemios de la Ilíada - y la primera parte del canto II actuarían de engarce, aunque situando la cólera de Aquiles y su disputa con Agamenón en el centro del hipotético argumento; pero a partir de ahí y hasta el canto VII nos encontraríamos con un poema temáticamente dependiente del Juicio de Paris, por lo que el autor lo denomina Paríada, y que se situaría cronológicamente en el primer año de la guerra, con los aqueos recién desembarcados.

El canto VIII supondría una transición - «un galimatías», dice el autor -, los cantos IX y X serían «ensayos libres», y en el canto XI daría comienzo la que podría llamarse Aquileida: se reemprendería la acción interrumpida en el canto II, Aquiles - que «a decir verdad, hasta ese momento, 
solo ha hecho tres cosas: insultar, enfurecerse y llorar» - recuperaría su principalía y ya la mantendría hasta el final, tal vez con digresiones como los juegos funerarios por Patroclo o la devolución a Príamo del cadáver de Héctor. Esta Aquileida se situaría en el noveno año de la guerra.

Esta dualidad estructural se correspondería con una doble cólera de Aquiles: la motivada por la disputa con Agamenón, y la provocada por la muerte de Patroclo, contra los troyanos en general y Héctor en particular. A nuestro entender, esta sección es el centro de gravedad de Ensayo sobre la Ilíada, la de más agradable lectura y la que hubiera justificado por si sola un trabajo.

Finalmente, los tres capítulos finales, bajo el epígrafe general de «La se- mántica» abordan el carácter abstracto de la Ilíada y algunos aspectos menores, que en parte podrían considerarse «éticos» del poema, y vienen, en suma, a mostrar implícitamente y a desarrollar una idea que el autor avanza en el final del prólogo: «que la Ilíada, una obra regocijante para el lector, es realmente un poema triste, así como que, consiguientemente, en él nadie, absolutamente nadie, ni soldado raso ni héroe o heroína ni divinidad, es feliz». Pero es esta tragicidad, precisamente, la que nos causa la fascinación a que al principio aludíamos, y la que dará pie, sin duda, a más estudios sobre el tema. 